\title{
A CONVENÇÃO EUROPEIA DE DIREITOS HUMANOS - UMA CONSTITUIÇÃO PARA A EUROPA? ${ }^{1}$
}

\author{
Angelika Nussberger \\ Doutora em Direito pela Universidade de Würzburg. Livre-Docente pela Universidade de \\ Munique. Vice-Presidente da Corte Europeia de Direitos Humanos (EGMR). Professora da \\ Universidade de Colônia.
}

Traduzido do alemão por Italo Roberto Fuhrmann.

\begin{abstract}
Resumo: Em retrospectiva, apresenta-se como surpreendente o ceticismo inicial constatado diante da Convenção Europeia de Direitos Humanos e do novo sistema engendrado para a proteção de direitos humanos. Por contingências históricas favoráveis, seu desenvolvimento superou todas as expectativas. A jurisprudência mostrou elementos revolucionários, os quais podem ser vistos como indicativos de uma constitucionalização. Muito embora a CEDH trate igualmente sobre a proteção da democracia e do Estado de Direito no contexto dos direitos humanos, ela, contudo, não pode ser considerada uma Constituição para a Europa.
\end{abstract}

Palavras-chave: Convenção Europeia de Direitos Humanos. Direito internacional. Constituição europeia. Direitos humanos. Constitucionalização.

Sumário: 1 Esperança e desilusão: o processo de formação - 2 Paciência e ideias inovadoras: o lento processo de maturação da CEDH - $\mathbf{3}$ Elementos para a constitucionalização - $\mathbf{4}$ Constituição ou algo diverso? - 5 A Corte Europeia de Direitos Humanos como Tribunal Constitucional ou como "Tribunal do Tratado do Modelo de Sociedade"? - $\mathbf{6}$ Crise e futuro - Referências

\section{Esperança e desilusão: o processo de formação}

Não foi um momento glorioso para a Europa. Quando foi dado o ponto final para a redação do texto da Convenção Europeia de Direitos Humanos (CEDH), em 4.11.1950, após dois anos e meio de deliberações, seus responsáveis, que queriam criar com este Tratado um mecanismo efetivo de proteção dos direitos humanos e limitar o entendimento, até então absoluto, de soberania estatal, não

1 Texto publicado originalmente na revista alemã Juristen Zeitung, ano 74, maio 2019. 0 presente artigo é uma versão escrita, com adição de notas de rodapé, da palestra proferida por ocasião da 59 Conferência de assistentes em Direito Público, realizada em Frankfurt, em 19.2.2019. O texto traduz exclusivamente a opinião da autora e não vincula, em nenhuma hipótese, a Corte Europeia de Direitos Humanos. 
estavam, de fato, dispostos a comemorar. O discurso do presidente do Conselho consultivo, o belga Paul-Henri Spaak, no início da cerimônia para a assinatura do Tratado, fala por si: “não é uma Convenção muito boa, porém o Palácio é belíssimo!”. ${ }^{2}$ Ele se referia ao Palácio Barberini, em Roma, local da cerimônia.

Por que o clima estava tão desfavorável, e o que se apresentava de tão lastimável? De uma primeira fase da redação do Tratado, envolta em grande entusiasmo, da qual participaram sobretudo técnicos e especialistas, ${ }^{3}$ seguiu-se uma segunda fase, em que representantes do governo levaram o clima esperançoso de volta para a realidade política. Os projetos inicialmente redigidos em consenso foram rejeitados, e o processo recomeçou do zero. Considerações políticas eram agora mais importantes do que questões técnicas de conteúdo. Especialmente o mecanismo de controle, tido como central para o cumprimento das obrigações, foi diluído. A ideia de um Tribunal que não apenas proferisse sentenças vinculativas, mas igualmente pudesse ordenar medidas de execução, ${ }^{4}$ foi abandonada. Ações individuais e controle judicial foram configurados como facultativos, e ao controle jurisdicional foi anteposto um filtro político. ${ }^{5}$

Em termos de conteúdo, as garantias jurídicas individuais foram concretizadas e formatadas em comparação com as primeiras versões. Por conta de controvérsias aparentemente insuperáveis, foram excluídos importantes direitos fundamentais, como o direito à propriedade e o direito à educação, atendendo à conjuntura política, de modo a facilitar as negociações para a conclusão, o mais rápido possível, do Tratado. Por detrás disso, estava o desejo de não só se declarar favorável aos direitos fundamentais, mas também, ante o início da Guerra Fria, de documentar essa declaração para o exterior. Assim esclareceu o político italiano Graf Sforza, na condição de presidente do comitê ministerial, segundo o qual se tratava de uma clara mensagem, demonstrada pela assinatura do Tratado, de que existia uma grande diferença - literalmente falando - entre "um mundo livre e um mundo escravizado, independentemente se os escravos estão ou não conscientes da sua escravidão". 6

2 Cf. BATES, Ed. The evolution of the European Convention on Human Rights. From its inception to the creation of a permanent Court of Human Rights. Oxford: Oxford University Press, 2010. p. 99.

3 Alguns autores do primeiro projeto (assim chamado "European Movement Convention") eram o antigo ministro da justiça francês Pierre-Henri Teitgen, o antigo substituto na chefia de acusação em Nuremberg Sir David Maxwell-Fyfe, e o membro belga da comissão de direitos humanos da ONU Fernand Dehousse.

4 Assim a disposição prevista no art. 13 (b) da "European Movement Convention", de acordo com as "measures of reparation".

5 Cf., em detalhes, em BATES, Ed. The evolution of the European Convention on Human Rights. From its inception to the creation of a permanent Court of Human Rights. Oxford: Oxford University Press, 2010. p. 118-131.

6 A citação pode ser encontrada em BATES, Ed. The evolution of the European Convention on Human Rights. From its inception to the creation of a permanent Court of Human Rights. Oxford: Oxford University Press, 2010. p. 99. 
Muitas coordenadas da desavença inicial permaneceram pendentes mais tarde. O conselho parlamentar e o comitê ministerial estavam contrapostos, sendo que o primeiro se sentia tratado pelo segundo como um "conselho de garotos de escola", e os representantes dos diversos países se acusavam mutuamente de dar primazia aos interesses nacionais em detrimento dos interesses da comunidade europeia. Conforme a opinião do chefe da delegação francesa Pierre-Henri Teitgen, os britânicos teriam "intimidado" o comitê ministerial, e conseguiram, como resultado, apenas a "sombra de uma garantia de direitos e liberdades fundamentais", num embate entre realistas e idealistas. ${ }^{7}$ Em resumo - foi desejado muito, porém pouco alcançado.

No entanto, assim como nos ensina a história do direito, o sucesso de uma Constituição ou de um Tratado não está no ambiente, no qual aqueles que nós metaforicamente gostamos de designar de "pais" ou "mães" finalizaram o seu trabalho. Alguns, aparentemente, almejam pouco e alcançam muito. 0 melhor exemplo é a atual Constituição alemã, elaborada como provisória, que comemora este ano seus orgulhosos 70 anos, e que serve como modelo de referência mundial. De modo contrário, há 100 anos a expectativa original em relação ao Tratado de Versalhes, de estabelecer um fundamento duradouro de uma ordem internacional pacífica, uma expectativa que já se mostrava uma utopia ao longo das deliberações, de fato, após alguns anos definitivamente caiu em descrédito. ${ }^{8}$ No âmbito da votação final para a Declaração Universal dos Direitos Humanos, Eleonor Roosevelt iniciou com as seguintes palavras "We stand today at the threshold of a great event both in the life of the United Nations and in the life of mankind, [...]. This Declaration may well become the international Magna Carta of all men everywhere". ${ }^{9}$ Este pathos não foi compartilhado por muitos dos presentes. Isso porque, ao mesmo tempo, já voavam, a cada três minutos e meio, os bombardeios de doces sobre Berlim, a Guerra Fria tinha começado. A Declaração Universal dos Direitos Humanos só conseguiu desenvolver força prática, na melhor das hipóteses, após a primeira década. Além disso, esperavase mais da Declaração, especialmente na condição de um Tratado de eficácia vinculante - o que, no transcorrer das deliberações, precisou ser retirado.

7 A citação pode ser encontrada em BATES, Ed. The evolution of the European Convention on Human Rights. From its inception to the creation of a permanent Court of Human Rights. Oxford: Oxford University Press, 2010. p. 100.

8 Cf., a representação pormenorizada das esperanças e decepções relativas ao Tratado de Paz, MACMILLAN, Margaret. Peacemaker. six months that changed the world. London: John Murray, 2003.

9 Declaração feita pela esposa de Franklin D. Roosevelt, no boletim do departamento de Estado, de 19.12.1948, p. 751-752, conforme citação de GLENDON, Mary Ann. A world made new. Eleonor Roosevelt and the Universal Declaration of Human Rights. New York: Random House Trade, 2001. p. 166. 
De forma similar, pode ser enquadrada a retrospectiva concernente à Convenção Europeia de Direitos Humanos. Seu "biógrafo", o jurista inglês Ed Bates, relatou que ela era praticamente nula na literatura científica da década de 1950, e até mesmo o inglês David Maxwell-Fyfe, um dos principais atores nas deliberações, em virtude de sua aparente pouca significação, dedicou apenas um curto parágrafo à Convenção em suas memórias. ${ }^{10}$ Nada obstante, após quase 70 anos, discutimos se a Convenção Europeia de Direitos Humanos não poderia ser de fato uma Constituição secreta para a Europa. Todo início parece ser complicado - será que a CEDH estava realmente sob bons auspícios?

\section{Paciência e ideias inovadoras: 0 lento processo de maturação da CEDH}

\subsection{Os primeiros anos}

Em regra, os tratados internacionais não são feitos para um futuro distante, mas para o presente. Assim que entram em vigor, geram os seus efeitos. Fronteiras são demarcadas, taxas alfandegárias são abolidas, obrigações são exigidas. Contrariamente a isso, parece ser uma característica dos tratados de direitos humanos a necessidade de um longo tempo, após a sua entrada em vigor, para amadurecer. Não que sejam inócuos, mas sua concretização demanda tempo.

Os principais atores da CEDH também estavam hesitantes, e sua postura era ambivalente. Isso valia especialmente para os britânicos. Deles veio a inspiração política - representada no nome de Churchill, ${ }^{11}$ bem como as ideias inovadoras para a sua implementação jurídico-legal. Sem Lauterpacht como pensador inicial ${ }^{12}$ e Maxwell-Fyfe como coautor, dificilmente a Convenção se tornaria o que de fato se tornou. Não obstante, podemos lembrar de um deputado trabalhista britânico que, como único contrário ao entusiasmo inicial envolto ao primeiro projeto, argumentava no sentido de que a Convenção não colaboraria em absoluto com a proteção dos direitos humanos, mas, pelo contrário, “criaria uma máquina cara e abusiva". ${ }^{13} \mathrm{E}$ apesar de o Reino Unido ter sido o primeiro a ratificar a

10 BATES, Ed. The evolution of the European Convention on Human Rights. From its inception to the creation of a permanent Court of Human Rights. Oxford: Oxford University Press, 2010. p. 11-12.

11 CHURCHILL, Winston. Discurso para a juventude acadêmica de 19 de setembro de 1946. Disponível em: https://rm.coe.int/16806981f3.

12 Cf., por todos, LAUTERPACHT, Sir Hersch. An International Bill of the Rights of Man. New York: Columbia University Press, 1945.

13 TP vol. Il art. 256, citado por BATES, Ed. The evolution of the European Convention on Human Rights. From its inception to the creation of a permanent Court of Human Rights. Oxford: Oxford University Press, 2010. p. 74 , nota de rodapé 143 . 
Convenção, em 8.3.1951, recusou-se a aceitar o sistema de petições individuais e a competência do Tribunal. Os britânicos também já tinham bloqueado todas as tentativas de assegurar o cumprimento das obrigações decorrentes da Convenção através de um controle obrigatório judicial. ${ }^{14}$ Os franceses tinham se posicionado a favor, porém, mais tarde, sequer ratificaram a Convenção. Somente em 1974 aderiram a ela, quando o Presidente Georges Pompidou sucedeu o Presidente Charles de Gaulle. E somente em 1981, sob a atuação do Ministro da Justiça Socialista Badinter, a França ratificou o protocolo para as petições individuais.

Mas mesmo quando o processo político se tornava mais lento, ele permanecia constante e sempre levava a uma determinada direção. Aos dez membros fundadores, entre os quais também a Turquia, se juntaram nos anos de 1950 e 1960, gradualmente, outros Estados de distintas partes geográficas da Europa, exceto do leste. O único revés no curso do seu desenvolvimento foi a retirada temporária da Grécia em virtude do golpe militar dos coronéis. Também na perspectiva jurídica, este foi um lento processo de criação. No início, havia igualmente um grande impacto - ainda pouco conhecido. Neste contexto, a Grécia trouxe a primeira reclamação de Estado contra o Reino Unido por conta dos métodos empregados para reprimir um levante na antiga colônia da coroa britânica do Chipre. A reclamação foi declarada como admissível. Um relatório de investigação constatou práticas inaceitáveis como açoites e punições coletivas. No entanto, nenhuma condenação foi concretizada, pois o Reino Unido, antes de uma possível condenação, aboliu a legislação controversa, e o processo, ainda que de forma não unânime, foi arquivado. As correspondentes resoluções do comitê ministerial foram publicadas em conjunto com os documentos relevantes apenas nos anos de 1997 e 2006. ${ }^{15}$ Ainda assim, este primeiro caso demonstrou como um controle externo pode gerar, ao fim, efeitos positivos.

Além disso, foram criadas na década de 1950 as mais importantes instituições, comissões e o próprio Tribunal. Os primeiros grandes casos, Lawless v. Irland,$^{16}$ o conflito belga do idioma ${ }^{17}$ e Golder v. Reino Unido, ${ }^{18}$ foram decisões paradigmáticas no desenvolvimento da jurisprudência da Corte, que cedo mostrou elementos inovadores, tanto em relação às garantias contidas na Convenção,

14 BATES, Ed. The evolution of the European Convention on Human Rights. From its inception to the creation of a permanent Court of Human Rights. Oxford: Oxford University Press, 2010. p. 457 e ss.

15 BATES, Ed. The evolution of the European Convention on Human Rights. From its inception to the creation of a permanent Court of Human Rights. Oxford: Oxford University Press, 2010. p. 195 e ss.

16 EUROPEAN COURT OF HUMAN RIGHTS. V. 14.11.1960, Nr. 332/57. Lawless v. Irland.

17 EUROPEAN COURT OF HUMAN RIGHTS. V. 23.07.1968, Nr. 1474/62; 1677/62; 1691/62; 1769/63; 1994/63; 2126/64.

18 EUROPEAN COURT OF HUMAN RIGHTS. V. 21.02.1975, Nr. 4451/70. Golder v. UK. 
quanto também em relação aos direitos implícitos, como o acesso para a postulação ao Tribunal e a interpretação das garantias da Convenção à luz do princípio do Estado de Direto. ${ }^{19}$ Nada obstante, na década de 1960 e no início da década de 1970, ninguém teria cogitado a ideia de se falar em uma “Constituição para a Europa” com vistas à CEDH. Muito pelo contrário, a Convenção era quando muito conhecida por um limitado círculo de iniciados. Quem porventura falasse sobre ela falaria - como o membro da comissão Jochen Frowein - da metáfora da "bela adormecida". ${ }^{20}$

\subsection{9 como mudança de paradigma?}

O historiador americano Samuel Moyn escreveu um livro sobre a história dos direitos humanos sob o belo título $A$ última utopia. A sua tese é de que os direitos humanos, diferentemente do que em geral se entende, não eram um fator político expressivo logo após a guerra e o holocausto, mas tão somente nos anos de 1970 surgiu um verdadeiro movimento social baseado nos direitos humanos. ${ }^{21}$ Ele o concebe como se fosse uma "explosão", uma série de catalisadores à procura de uma identidade europeia, que não se definisse apenas nas categorias da Guerra Fria, oriunda do encontro de políticos, jornalistas e intelectuais com os dissidentes soviéticos e depois do leste europeu, e da moralização da política externa americana após o trauma da Guerra do Vietnã - podemos pensar aqui no discurso de Jimmy Carter na Universidade de Notre Dame aos 22.5.1977, no qual ele tentou colocar a política externa americana numa nova base de legitimação, e elevar a reputação dos EUA no mundo ao promover uma nova campanha norteamericana para os direitos humanos. ${ }^{22}$ Todos esses foram sinais da ruptura com as utopias, até então válidas, formuladas a partir do modelo capitalista ou comunista. ${ }^{23} \mathrm{~A}$ referência aos direitos humanos só se tornou um "bem comum" não só no discurso político, mas no discurso em geral, na década de 1970.

19 Nussberger, in NOLTE; KRIEGER (Org.). Rule of Law. [s.I.]: [s.n.], [s.d.].

20 FROWEIN, Jochen. European integration through fundamental rights. Michigan Journal of Law Reform, Ann Arbor, v. 18, n. 1, p. 5-27, 1984. Disponível em: https://repository.law.umich.edu/mjlr/vol18/iss1/2/.

21 MOYN, Samuel. The Last Utopia: Human Rights in History. Cambridge: Harvard University Press, 2012. p. 8.

22 Discurso de Carter na Universidade de Notre Dame em 22.5.1977 (PUBLIC PAPERS OF THE PRESIDENTS OF THE UNITED STATES. Jimmy Carter: 1977, v. 1. Washington D.C.: GPO, 1977. Disponível em: https:// quod.lib.umich.edu/p/ppotpus?key=title;page=browse;value=j).

23 MOYN, Samuel. The Last Utopia: Human Rights in History. Cambridge: Harvard University Press, 2012. p. 8. "These were belief systems that promised a free way of life, but led into bloody morass, or offered emancipation from empire and capital, but suddenly came to seem like dark tragedies rather than bright hopes. In this atmosphere, an internationalism revolving around individual rights surged, and it did so because it was defined as a pure alternative in an age of ideological betrayal and political collapse". 
Mudança de paradigma 1979 foi o título dado pelo historiador Frank Bösch à sua análise sobre a época, publicada no início de 2019. Seu livro traz como subtítulo: "Como o mundo de hoje começou". A tese é de que "as fontes de nosso presente" poderiam ser encontradas no ano de 1979 - ou seja, há quarenta anos -, um ano que também para Peter Sloterdijk é a "data chave para o século XX". ${ }^{24}$ Pontos importantes da história no contexto nacional - alemão - e internacional são a abertura da China, a revolução islâmica em Teerã, a fusão dos verdes e sua entrada no primeiro parlamento estadual, o acidente do reator em Harrisburg, protestos em Gorleben, a eleição de Margaret Thatcher como primeira-ministra, a visita do Papa João Paulo à Polônia, a boat people vietnamita, a revolução na Nicarágua, a tomada de reféns na embaixada americana em Teerã, a dupla resolução da Otan, e finalmente a invasão no Afeganistão. Tudo isso aconteceu em um ano.

Pode até ser um acaso, porém é de fato significativo que justamente no ano de 1979 foram proferidas as duas decisões da Corte Europeia de Direitos Humanos, que também serviram para uma mudança de paradigma na jurisprudência de direitos humanos: Tyrer v. Reino Unido ${ }^{25}$ e Marckx v. Belgien. ${ }^{26}$ Os temas eram, de um lado, a proibição de castigos corporais em crianças, e, de outro, o tratamento desigual de crianças nascidas fora do casamento. Numa tripla perspectiva, estes dois processos mudaram os rumos para o futuro e - pode-se afirmar, sem qualquer exagero, que foram os pressupostos para a conquista do que hoje se denomina "constitucionalização" ou "ordre public européen". Em primeiro lugar, foi criada a "living-instrument-Doktrin", e com isso a Convenção, que já tinha quase 30 anos, foi liberta das amarras do período histórico de sua época; em segundo lugar, através da "margin-of-appreciation-Doktrin" que tornou maleável a engrenagem entre a jurisprudência nacional e internacional dos direitos humanos, e em terceiro lugar, ousou em dar um passo em direção ao acesso à legislação nacional, em especial ao direito civil, e testá-la à luz dos parâmetros internacionais.

Era um Tribunal tão internacional, mas ainda muito pouco conhecido, que deu à política, no final da década de 1970, uma nova concepção de soberania, baseada no direito dos tratados internacionais, e desde então reiteradas vezes pensada, discutida e criticada, assim como o Tribunal de Luxemburgo, que havia colocado em xeque, uma década e meia antes, o clássico conceito de soberania mediante um novum de um direito supranacional. ${ }^{27}$ Também a Corte de Estrasburgo não aceitava mais o isolamento e a presunção dos Estados Nacionais - pelo menos

\footnotetext{
24 SLOTERDIJK, Peter. Zorn und Zeit. Berlim: Suhrkamp Verlag, 2016. p. 336 e ss.

25 EUROPEAN COURT OF HUMAN RIGHTS, v. 25.04.1978, Nr. 5856/72 - Tyrer v. UK.

26 EUROPEAN COURT OF HUMAN RIGHTS, v. 13.06.1979, Nr. 6833/74 - Marckx v. Belgien.

27 EuGH v. 05.02.1963 - 26/62, van Gend en loos, ECLI:EU:C:1963:1.
} 
em questões concernentes aos direitos humanos. A depender do ponto de vista, é possível visualizar esse novo princípio interpretativo desenvolvido em 1979 já como uma consequente interpretação inserta desde o início na Convenção em seu mecanismo de controle, ou, uma ação exorbitante, de um autoempoderamento não abrangido por uma norma de competência. De qualquer forma, foi no ano de 1979 que o Tribunal decidiu sobre os direitos das crianças nascidas fora do matrimônio e dos jovens castigados com punições físicas, e que foi criado o fundamento que o mesmo Tribunal, no ano de 2019, utilizou para decidir sobre casos levados à Corte por transexuais que deram à luz filhos como mulheres, mas queriam se registar como pais e não como mães, ${ }^{28}$ casos de refugiados no Líbano, que bateram à porta do consulado de um dos Estados-Membros da Convenção e que desejavam ingressar com fundamento na Convenção, ${ }^{29}$ e casos de criminosos condenados, que discutiam sobre o tamanho de suas celas. ${ }^{30}$ Quando as portas de um tribunal estão amplamente abertas, ele deve decidir. Sobre tudo. E isso traz consequências para o Estado e para a sociedade.

\section{Elementos para a constitucionalização ${ }^{31}$}

\subsection{De um controle pontual a um controle abrangente}

O questionamento sobre por que as decisões nos casos Marckx e Tyrer introduziram uma mudança de paradigma na proteção dos direitos humanos pode ser respondido pelos distintos votos da maioria e da minoria.

No seu voto divergente no caso Marckx v. Bélgica, ocupou-se ninguém menos do que o Juiz britânico Sir Gerald Fitzmaurice - antigo membro da Comissão de Direito Internacional Público, juiz da Corte Internacional de Justiça, e tão famoso que até um cabo na costa leste da península antártica leva o seu nome - segundo o qual, literalmente, "uma pequena voz da consciência jurídica" que se opõe "ao desejo de alcançar determinados resultados, por mais meritórios que possam ser". ${ }^{32}$ O fino humor britânico não deve atenuar a crítica fundamental expressa

28 EUROPEAN COURT OF HUMAN RIGHTS, Nr. 53568/18 e 54941/18, O.H. and G.H v. Alemanha.

29 EUROPEAN COURT OF HUMAN RIGHTS, Nr. 3599/18 - M.N u.a.v Bélgica.

30 Decisão paradigmática. EUROPEAN COURT OF HUMAN RIGHTS, v. 20.10.2016, Nr. 7334/13 - Mursic v. Croácia.

31 Sobre o processo de constitucionalização na Europa com fundamento na CEDH existe uma vasta literatura; cf. por todos, Walter ZaöRV 1999, 962-983; ibidem ZaöRV 2015, 753-770; Schaefer EuR 2017, 80-106; Tomuschat EuGRZ 2003, 95-100.

32 FITZMAURICE, Gerald. Voto minoritário em EUROPEAN COURT OF HUMAN RIGHTS, v. 13.06.1979, Nr. 6833/74, Marckx v. Bélgica, número de margem 5. 
nas palavras do juiz. Na sua opinião, o voto da maioria no caso Marckx não seria juridicamente fundamentável, já que as fronteiras entre a decisão política e jurídica teriam sido removidas. Teríamos ido muito longe. "Within certain limits almost anything can colourably be represented as connected with or related to some other given thing", escreveu ele. ${ }^{33}$ De alguma forma, tudo teria uma relação com tudo. Nesta senda, tudo poderia, teoricamente, sob uma disposição normativa da Convenção, especialmente sobre a vida privada e familiar, ser considerado protegido. As regras de subsunção não admitem uma margem tão ampla para a interpretação, de modo a não falsificar a ideia fundamental da Convenção de garantia contra ataques de um Estado totalitário ou ditatorial. Um regramento sobre descendência seria uma categoria jurídica totalmente distinta em relação “à vida familiar”, e não seria a ela subsumível.

A interpretação da maioria seria: “[...] little else but a misguided endeavour to read - or rather introduce - a whole code of family law into Article 8 (art. 8) of the Convention, thus inflating it in a manner, and to an extent, wholly incommensurable with its true and intended proportions". ${ }^{34}$

Esta discussão, em última análise, gira em torno da questão fundamental sobre se os direitos humanos abrangem todos os aspectos da existência humana, ou se apenas determinadas dimensões são protegidas. A ideia que prevaleceu foi a de uma proteção abrangente que, na melhor das hipóteses, deixa poucas lacunas. "Possible repercussions on family life are not enough to make a thing part of it", escreve Fitzmaurice. ${ }^{35}$ Porém, como mostra a ideia prevalecente da maioria "possible repercussions" são suficientes. Com isso, o controle com base nos direitos humanos não se realiza apenas numa perspectiva panorâmica, mas também por meio de uma lupa para verificar o que acontece dentro de um EstadoMembro. A legislação nacional, como o direito de família no caso Marckx, se tornou passível de controle perante a Corte Europeia de Direitos Humanos. E com isso, o papel da Corte Europeia de Direitos Humanos, de repente, se equipara a do Tribunal Constitucional - e isso é o início de uma transformação maravilhosa. Isso se aplica ainda mais na medida em que as consequências das decisões se assemelham. Ainda que as decisões da EGMR não tenham um efeito de cassação, as autoridades nacionais são obrigadas a adaptar o direito conforme

33 FITZMAURICE, Gerald. Voto minoritário em EUROPEAN COURT OF HUMAN RIGHTS, v. 13.06.1979, Nr. 6833/74, Marckx v. Bélgica, número de margem 5.

34 FITZMAURICE, Gerald. Voto minoritário em EUROPEAN COURT OF HUMAN RIGHTS, v. 13.06.1979, Nr. 6833/74, Marckx v. Bélgica, número de margem 15.

35 FITZMAURICE, Gerald. Voto minoritário em EUROPEAN COURT OF HUMAN RIGHTS, v. 13.06.1979, Nr. 6833/74, Marckx v. Bélgica, número de margem 15. 
a Convenção, se não quiserem ser condenadas novamente. ${ }^{36}$ Este é um dever de direito internacional público, o qual o Comitê Ministerial supervisiona. ${ }^{37}$

Deve-se acrescentar que a discussão sobre os limites da interpretação do art. 8ำ da CEDH se equipara à discussão iniciada por Dieter Grimm com o seu voto divergente designado "cavalgar na floresta". ${ }^{38}$ Entretanto, podemos caracterizar 0 art. $8^{\circ}$ da CEDH - similar ao art. 2ำ da Lei Fundamental alemã - como um direito fundamental de acesso. Nada obstante, há controvérsias em que os limites ainda estão para ser definidos. Um exemplo ilustrativo de tempo recente é o caso di Trizio v. Schweiz, ${ }^{39}$ no qual a maioria também interpretou a concessão de determinada prestação social como um aspecto da "vida familiar", enquanto a minoria argumentou pela subsunção exclusiva ao art. 1ํ do protocolo 1.40 A questão central é se com mais dinheiro há “mais família”, ou, inversamente, se a vida familiar é restringida, se o Estado põe à disposição menos dinheiro. De forma similar, é possível indagar se o poder de disposição sobre os óvulos fertilizados constitui parte da vida privada. ${ }^{41}$ Esses exemplos mostram até onde as "repercussions" tematizadas por Fitzmaurice podem chegar. Suas dúvidas não são simplesmente um "registro" ou um despojo da história. Mas sempre retornam e nos levam diretamente à pergunta de, e em caso afirmativo, como um tratado de direito internacional público pode se transformar em uma Constituição ou em uma quase Constituição.

\subsection{Renúncia à interpretação histórica}

Os métodos de interpretação de um tratado de direito internacional público, em comparação com outros ramos do direito, caracterizam-se pela menor importância atribuída à interpretação histórica. De acordo com a Convenção de Viena sobre o Direito dos Tratados, ela deve ser considerada apenas de forma subsidiária, ou para confirmar determinada interpretação resultante de outros métodos interpretativos, ou para esclarecer uma interpretação ambígua, obscura,

\footnotetext{
36 Cf., art. 46, §1ํㅡ, CEDH: “os Estados-parte da Convenção se comprometem a cumprir a decisão final do Tribunal em todos os casos em que sejam parte".

37 Cf., art. 46, §2º, CEDH: “A decisão definitiva do Tribunal deve ser comunicada ao comitê ministerial. Este deve supervisionar sua implementação".

38 BVerGE 80, 137, 164.

39 EUROPEAN COURT OF HUMAN RIGHTS, v. 02.02.2016, Nr. 7186/09 - Di Trizio v. Schweiz.

40 Keller, Spano, Kjolbro, voto da minoria em EUROPEAN COURT OF HUMAN RIGHTS, v. 02.02.2016, Nr. 7186/09 - Di Trizio v. Schweiz.

41 EUROPEAN COURT OF HUMAN RIGHTS, v. 28.05.2013, Nr. 46470/11 - Parrillo v. Italy.
} 
absurda ou irracional. ${ }^{42}$ Ambas as decisões Marckx e Tyrer vão, no entanto, além da Convenção de Viena sobre o Direito dos Tratados.

Uma interpretação que não apenas desconsidere a intenção histórica, mas a contradiga expressamente, pode ser necessária sob certas circunstâncias, já que de outro modo o espírito de uma época, como o espírito que prevalecia em relação à CEDH nas décadas de 1940 e 1950, seria determinante, e com isso a Convenção perderia sua atualidade e significado. A CEDH é, como preceituado no aforismo, um "living instrument". ${ }^{43}$ Em termos dogmáticos, esta compreensão se relaciona a uma outra disposição da Convenção de Viena sobre o Direito dos Tratados, a saber o art. 33, §3으, alínea “b”, de modo que toda e qualquer aplicação futura da Convenção deverá levar em conta a concordância das partes envolvidas sobre sua interpretação. Uma “aplicação futura” é também um novo consenso na sociedade.

Com essa abordagem, foram caracterizados como "tratamento desumano" os castigos físicos, e o tratamento discriminatório de filhos nascidos fora do casamento como contrário à Convenção, embora não se possa questionar que ambos os casos eram perfeitamente aceitos pela sociedade nos anos de 1940 e 1950. Consoante as palavras do antigo presidente do Tribunal, Sir. Niklas Bratza, a chamada "living-instrument-Doktrin" possibilitou "to breathe life into the words of the instrument so as to make it relevant to contemporary European Society". ${ }^{44}$

No direito internacional público, as obrigações contraídas pelos Estados passam a ser adaptadas ao processo de evolução da sociedade, e isso é um Novum (sem precedentes). Com isso, basicamente, um dos principais déficits dos tratados internacionais multilaterais foi equacionado - a rigidez de alterações por conta da necessária unanimidade. A Lei Fundamental alemã, nos seus 70 anos de existência, foi modificada 62 vezes, já as disposições substanciais da CEDH, ao contrário, não foram alteradas nem uma única vez; simplesmente complementada através de protocolos. Assim permanece até hoje a pena de morte no art. 2ํ da CEDH; e o catálogo das proibições de discriminação não contém critérios como da "orientação sexual". Porém, num contexto de "living instrument" podemos facilmente ignorar tais referências e lacunas históricas. No presente, podemos identificar o tratamento igualitário entre homens e mulheres e a abolição da pena de morte como conquistas “Acquis" sob o fundamento da CEDH, e como conditio sine qua non para a adesão de novos membros no Conselho da Europa,

\footnotetext{
42 Art. 32, da Convenção de Viena sobre o Direito dos Tratados, de 23.05.1969, BGB1, 1985 II, p. 926.

43 EUROPEAN COURT OF HUMAN RIGHTS, v. 13.06.1979, Nr. 6833/74 - Marckx v. Belgien, número de margem 41; EUROPEAN COURT OF HUMAN RIGHTS, v. 25.04.1978, Nr. 5856/72 - Tyrer v. UK, número de margem 31.

44 BRATZA, Niklas. European Human Rights Law Review, Oxford, v. 2, 2014. p. 118.
} 
de modo que é necessário admitir que alguns Estados fundantes em 1953 teriam dificuldades, à época, de preencher tais pressupostos.

\subsection{Margin of appreciation}

E, finalmente, será analisado no âmbito de julgamento da decisão Marckx, o entendimento, não da maioria, mas, no entanto, o do já citado Juiz Fitzmaurice. Ele defende a lei regulamentadora belga, segundo a qual as mães de crianças ilegítimas não seriam ex lege mães de seus filhos; uma tal regulamentação estaria "well within the margin of appreciation or discretion that any Government, acting bona fide, ought to be accorded". ${ }^{45}$ E continua: “[...] in any event, States must be allowed to change their attitudes in their own good time, in their own way and by reasonable means, - States must be allowed a certain latitude". ${ }^{46} 0$ recurso à margem de apreciação já é, a essa altura, uma figura argumentativa reiteradamente aplicada na jurisprudência do Tribunal, e que posteriormente começa a se desenvolver como o puxar de um fio através da jurisprudência. ${ }^{47}$ Muitas vezes, dividem-se os peticionantes sobre a "margem"; aqueles que pleiteiam por uma violação da Convenção negam a "margem"; aqueles que argumentam o contrário reconhecem uma ampla margem. o exemplo mais conhecido é o crucifixo nas salas de aula, a chamada decisão Lautsi, na qual distintos resultados das câmaras ${ }^{48}$ e da grande câmara ${ }^{49}$ são devidos essencialmente a essa "margem". Trata-se do nível de unidade e diversidade que é desejado, e com isso cria-se uma premissa para a decisão, que é tomada através de múltiplos critérios, mas que se distancia de um resultado calculado. A jurisprudência da Convenção é, em última análise, um modelo de semáforo - "vermelho", “amarelo" e "verde". Entre o que é compatível com a Convenção ("verde") e o que viola a Convenção ("vermelho"), existe uma área, na qual o Tribunal considera várias soluções possíveis. Parar ou continuar

45 FITZMAURICE, Gerald. Voto minoritário em EUROPEAN COURT OF HUMAN RIGHTS, v. 13.06.1979, Nr. 6833/74, Marckx v. Bélgica, número de margem 29.

46 FITZMAURICE, Gerald. Voto minoritário em EUROPEAN COURT OF HUMAN RIGHTS, v. 13.06.1979, Nr. 6833/74, Marckx v. Bélgica, número de margem 29.

47 ASCHE, Josephine. Die Margin of Appreciation. Berlim: Springer, 2018; Binder, JRP 2015, 1; GREER, S. C. The Interpretation of the European Convention on Human Rights: Universal principle or margin of appreciation? UCL Human Rights Review, Oxford, v. 3, 2010; LEGG, Andrew. The Margin of Appreciation in International Human Rights Law. Deference and Proportionality. Oxford: Oxford University Press, 2012; LETSAS. In: ETINSON, Adam (Org.). Human rights: moral or political? Oxford: Oxford University Press, 2018; TITIUN, Patrick (Org.). La conscience de droits: Mélanges en l'honneur de Jean-Paul Costa. Paris: Dalloz, 2011. p. 527.

48 EUROPEAN COURT OF HUMAN RIGHTS, v. 03.11.2009, Nr. 30814/06 - Lautsi v. Itália.

49 EUROPEAN COURT OF HUMAN RIGHTS (GK), v. 18.03.2011, Nr. 30814/06 - Lautsi v. Itália. 
dirigindo é igualmente permitido. Se o incesto entre irmãos é punível ou não, ${ }^{50}$ se o naturismo é tolerável, ${ }^{51}$ se se admite a eutanásia, ${ }^{52}$ tudo isso é uma questão de "margem". Caso haja um consenso europeu, este pode ser um caminho a ser seguido, mas não significa que seja obrigatório. ${ }^{53}$

Todos estes pensamentos encontram-se pela primeira vez agrupados no caso Marckx v. Bélgica. Com isso, não há nenhum exagero em afirmar que, da mesma forma como a decisão $L u ̈ t h^{54}$ está para Karlsruhe, a decisão Marckx está para Estrasburgo.

Essas reflexões nos levam à pergunta sobre quais as funções de uma Constituição. No caso Lüth, foi engendrado um sistema de valores. E por detrás deste sistema de valores estava uma nova identidade, uma identidade constitucional.

\section{Constituição ou algo diverso?}

Desta forma, a retrospectiva histórica nos leva a esta questão: seria a CEDH, por conta desta nada menos revolucionária abordagem interpretativa, desenvolvida no ano de 1979, uma Constituição? - A resposta é clara. Não, a CEDH não é uma Constituição. Faltam: em primeiro lugar, um Estado. Em segundo lugar, art. 21 ao art. 146. E em terceiro lugar, a última palavra. Isso deve ser explicado na sequência de forma detalhada.

\subsection{Comunidade de Estados-Membros vs. Estado}

À CEDH falta o Estado. Não existe povo, território e governo. As categorias indicadas não são preenchidas. Ao invés disso, "os europeus" são amplamente compreendidos como aqueles que vivem de modo temporário ou permanente em qualquer dos 47 Estados-Membros, de modo que há um "espaço jurídico

\footnotetext{
EUROPEAN COURT OF HUMAN RIGHTS, v. 12.04.2012, Nr. 43547/08 - Stübing v. Alemanha.

EUROPEAN COURT OF HUMAN RIGHTS, v. 28.10.2014, Nr. 49327/11 - Gough v. Reino Unido.

EUROPEAN COURT OF HUMAN RIGHTS, v. 05.06.2015, Nr. 46043/14, - Lambert v. França.

53 DZEHTSIAROU, Kanstantsin. European consensus and the legitimacy of the European Court of Human Rights. Cambridge: Cambridge University Press, 2015; DOTHAN, Shai. Judicial deference allows European Consensus to Emerge. Chicago Journal of International Law, v. 18, 2018; KLEINLEIN, Thomas. Consensus and Contestability: The ECtHR and the Combined Potential of European Consensus and Procedural Rationality Control. European Journal of International Law, v. 28, 2017; Nußberger RW 2012, 197; UngerSternberg AVR 2013, 312.

54 BVerfGE 7, 198, Cf., por todos, as contribuições específicas em HENNE, Thomas; RIEDLINGER, Arne (Hrsg.). Das Lüth-Urteil aus (rechts-) historischer Sicht. die Konflikte umVeit Harlan und die Grundrechtsjudikatur des Bundesverfassungsgerichts, 2005.
} 
europeu", que se evidencia como abstrato. Tal espaço não se limita às fronteiras da Europa, mas o conceito de jurisdição pode ser compreendido de forma ampla. ${ }^{55}$ $\mathrm{E}$, finalmente, existe a obrigação de direito internacional, de cumprir os tratados internacionais, um dever que, no entanto, só pode ser aplicado de forma limitada. Ao contrário de um poder estatal, não há um “poder estatal do tratado", nem deveria haver.

\subsection{Organização estatal abrangente vs. definição de um modelo de sociedade}

A CEDH não contém nenhuma regra sobre as autoestradas federais nem sobre compensação financeira. Definições detalhadas sobre organização estatal, assim como dispostas na Lei Fundamental alemã do art. 21 ao art. 146, faltam à Convenção. Contudo, ela é mais do que somente um catálogo de direitos fundamentais. Os princípios estruturantes dispostos no art. 20 da Lei Fundamental também podem ser encontrados na CEDH: democracia, Estado de Direito, Estado Social. E até mesmo elementos do federalismo foram previstos.

\subsubsection{Princípio democrático}

Isso vale, em primeiro lugar, para o princípio da democracia. A fórmula "necessary in a democratic society" 56 é a base de todo e qualquer processo de ponderação. Eleições democráticas estão previstas no art. 3o, Protocolo I. ${ }^{57}$ No que concerne ao pluralismo e à tolerância, o Tribunal apontou, na sua jurisprudência, o caminho dos arts. 10 e 11. Na mais recente jurisprudência da Corte, a amplitude da margem também é determinada processualmente - quanto mais intensa e

55 BESSON, Samantha. The extraterritoriality of the European Convention on Human Rights. Leiden Journal of International Law, v. 25, 2012; BHUTA, Nehal (Org.). The frontiers of human rights: extraterritoriality and its challenges. Oxford: Oxford University Press, 2016; JANKOWSKA-GILBERG, Magdalena. Extraterritorialität der Menschenrechte. Berlim: Nomos Verlagsgesellschaft, 2008; MILANOVIC, Marko. Extraterritorial Application of Human Rights Treaties. Oxford: Oxford University Press, 2011; MILANOVIC, Marko. From Compromise to Principle. Human Rights Law Review, v. 8, 2008; MILANOVIC, Marko; PAPIC, Tatjana. The applicability of the ECHR in contested territories. International and Comparative Law Quaterly, v. 67, 2018; NUßBERGER, Angelika. The Concept of 'Jurisdiction' in the Jurisprudence of the European Court of Human Rights. Current Legal Problems, v. 65, 2012.

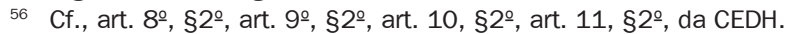

57 “Os Estados-partes na Convenção se obrigam, em períodos adequados, a realizar eleições livres e secretas, em condições que garantam a livre expressão da opinião do povo na composição dos órgãos legislativos". 
aberta uma matéria for tratada no processo legislativo, maior espaço de atuação é deixado ao legislador nacional; com isso são feitas prescrições indiretas, mas importantes, para o processo legislativo. ${ }^{58} \mathrm{~A}$ separação dos poderes também é um pressuposto exigido. De forma detalhada, é a discussão sobre o processo justo, por exemplo, quando se trata do âmbito do controle das decisões executivas. ${ }^{59}$

\subsubsection{O princípio do Estado de Direito}

Também o princípio do Estado de Direito desempenha um papel central. Embora esteja previsto apenas no preâmbulo da CEDH, é, entretanto, um consenso que as garantias individuais devem ser interpretadas à luz do princípio do Estado de Direito. Como as restrições a direitos fundamentais devem se basear na lei, o Tribunal desenvolveu uma variada jurisprudência sobre a qualidade das leis, previsibilidade e segurança jurídica, também sobre a densidade regulatória - por último sobre medidas de interceptação. Garantias como "processo justo", nulla poena sine lege, ne bis in idem e independência da justiça são partes fundamentais da compreensão sobre o Estado de Direito. ${ }^{60}$

\subsubsection{Princípio do Estado Social}

E também ideias de Estado Social podem ser igualmente extraídas, por exemplo, se uma segurança existencial for exigida pelo art. 3ํ da CEDH (proibição de tratamento desumano), ${ }^{61}$ ou pensões e outras prestações sociais garantidas legalmente, que são protegidas pelo direito de propriedade. ${ }^{62} \mathrm{~A}$ diferenciação das famosas "obrigações positivas" transforma um Estado puramente liberal em um

58 NUßBERGER, in: GERARDS, Janneke; BREMS, Eva (Org.). Procedural review in European fundamental rights cases. Cambridge: Cambridge University Press, 2017. p. 161.

59 EUROPEAN COURT OF HUMAN RIGHTS, v. 6. 11. 2018, Nr. 55 391/13, 57 728/13 e 74 041/13 - Ramos Nunes de Carvalho e Sá, §§204 ss.; ver também sobre isso Concurring Opinion von Raimondi, Nußberger, Jäderblom, Møse, Pola' čkova', Koskelo.

60 NUßBERGER, in: ZUBIK, Marek (Org.). Human Rights in Contemporary World. Essays in Honour of Professor Leszek Garlicki. Warschau: Wydawnictwo Sejmowe, 2017. p. 162-173.

61 EUROPEAN COURT OF HUMAN RIGHTS, v. 23. 4.2002, Nr. 56 869/00 - Larioshina v. Federação Russa; EUROPEAN COURT OF HUMAN RIGHTS, v. 21.1.2011, Nr. 30 696/09 - M.S.S. v. Grécia e Bélgica; EUROPEAN COURT OF HUMAN RIGHTS, v. 24.5.2018, Nr. 6882/13 - N.T.P u. a. v. França.

62 Cf., o desenvolvimento da jurisprudência do EUROPEAN COURT OF HUMAN RIGHTS, v. 16. 9.1996, Nr. 17 371/90 - Gaygususz v. Österreich até EUROPEAN COURT OF HUMAN RIGHTS (GK), v. 13.12.2016, Nr. 53 080/13 - Belane Nagy v. Hungria. 
Estado responsável pelo bem-estar e aflições do indivíduo. ${ }^{63} \mathrm{Na} C E D H$, não estão previstos direitos fundamentais sociais, porém, a exigência de sua proteção pela CEDH é mais efetiva do que a proteção garantida pelos diversos pactos sociais, como exemplo, a Carta Social europeia.

\subsubsection{Federalismo}

Também elementos de uma compreensão fundamental do federalismo podem ser identificados. Ante a entrada em vigor do protocolo 15, o princípio da subsidiariedade deve ser compreendido como um novo princípio fundamental no preâmbulo. ${ }^{64}$ Já é um pensamento dominante na jurisprudência. Quase que uma fórmula, segundo a qual as instituições nacionais são mais apropriadas para julgar as particularidades do caso concreto e as circunstâncias do local, e o Tribunal apenas intervém se todos os mecanismos internos falharem. ${ }^{65}$ Caso os Tribunais apliquem a $\mathrm{CEDH}$ ao caso concreto correspondente, e cheguem a determinado resultado, a Corte precisa de "muitos bons motivos" para decidir o caso de uma forma distinta. ${ }^{66}$ Robert Spano cunhou, para isso, o conceito de "uma nova era da subsidiariedade". ${ }^{67}$

A CEDH afirma um novo modelo de sociedade, cujos contornos são claros, mas que podem ser implementados em distintas formas. Nas palavras do Tribunal: "There [are] a wealth of differences, inter alia, in the historical development, cultural diversity and political thought within Europe which it is for each contracting state to mould into its own democratic vision". ${ }^{68}$ Desta forma, a CEDH não apenas

63 DRÖGE, Cordula. Positive Verpflichtungen der Staaten der Europäischen Menschenrechtskonvention. Berlim: Springer, 2003; Klatt ZaöRV 2011, 691; Krieger ZaöRV 2014, 187; MOWBRAY, Alastair. The development of positive obligations under the European Convention on Human Rights by the European Court of Human Rights. New York: Hart Publishing, 2004; STOYANOVA, Vladislava. The Disjunctive Structure of Positive Rights under the European Convention on Human Rights. Nordic Journal of International Law, v. 87, 2018; XENOS, Dimitris. The positive obligations of the state under the European Convention of Human Rights. Oxfordshire: Routledge, 2013.

64 Em processo de entrada em vigor; ratificado por 45 Estados (22.2.2019).

65 "The Convention leaves to each Contracting State, in the first place, the task of securing the rights and liberties it enshrines. The institutions created by it make their own contribution to this task but they become involved only through the contentious proceedings and once all domestic remedies have been exhausted" (EUROPEAN COURT OF HUMAN RIGHTS, v. 7.12.1976, Nr. 5493/72 - Handyside v. GrãBretanha, número de margem 48).

66 "Where the balancing exercise has been undertaken by the national authorities in conformity with the criteria laid down in the Court's case law, the Court would require strong reasons to substitute its view for that of the domestic courts" (EUROPEAN COURT OF HUMAN RIGHTS, v. 7. 2. 2012, Nr. $40660 / 08$, 60 641/08 - von Hannover v. Alemanha, número de margem 107).

67 SPANO, Robert. The Future of the European Court of Human Rights. Subsidiarity, Process-Based Review and the Rule of Law. Human Rights Law Review, v. 18, 2018.

68 EUROPEAN COURT OF HUMAN RIGHTS, v. 7. 5. 2013, Nr. 19 840/09 - Shindler v. Reino Unido. 
admite diferentes possibilidades de formação e variantes sobre o tema "Estado Democrático e Social de Direito", mas exige que haja uma riqueza de variantes. Diferentemente do modelo de Estado federado previsto na Lei Fundamental alemã, não existe nenhum imperativo de harmonia, nenhuma previsão para a "produção de relações equitativas de convivência", ou para a "preservação de uma unidade econômica e jurídica num interesse geral de Estado". 69 O enquadramento federativo é maleável e flexível.

Em 60 anos de jurisprudência, foi criado um modelo de sociedade consistente a partir de garantias específicas de direitos fundamentais. Contudo, faltam - em contraste com a Constituição - precisamente os arts. 21 a 146, as regulamentações detalhadas sobre legislação, organização do Executivo, e o fluxo financeiro. Com efeito, existem espaços vazios na $\mathrm{CEDH}$, que não podem ser preenchidos com disposições gerais.

\subsection{A última vs. a penúltima palavra}

A citação do Tribunal Constitucional alemão no caso Görgülü, segundo o qual a Lei Fundamental não renuncia "a soberania posta na última palavra da Constituição alemã", é famosa, para não dizer famigerada. ${ }^{70}$ Esta "última palavra" também é reivindicada pela CEDH na condição de tratado de direito internacional público, já que um conflito com o direito constitucional, como parte do direito nacional, não justifica o não cumprimento de um tratado de direito internacional. 0 art. 27 da Convenção de Viena sobre o Direito dos Tratados é categórico neste sentido: “um Estado-parte no Tratado não pode se valer do direito interno para justificar o não-cumprimento de um Tratado". No entanto, aqui a lógica do sistema vai de encontro com a própria lógica do sistema, já que o direito constitucional se coloca igualmente numa posição de reivindicar a validade última. No que concerne ao direito europeu, o Tribunal de Justiça da União Europeia aparentemente solucionou ${ }^{71}$ o dilema no caso van Gend en $\operatorname{Loos}^{72} \mathrm{com}$ a reivindicação da supranacionalidade, porém, de acordo com Dieter Grimm, a um alto preço, já que foi postulado o que não foi realmente negociado. ${ }^{73}$ Os limites de ruptura

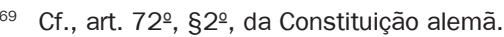

70 Decisões da Corte Constitucional alemã: 111, 307, 319.

71 Cf., para esse desenvolvimento, TERHECHTE, Jörg Philipp. Konstitutionalisierung und Normativität der europäischen Grundrechte. Tübingen: Mohr Siebeck, 2011. p. 41 e ss.

72 Tribunal de Justiça da União Europeia (Decisão paradigmática. EUROPEAN COURT OF HUMAN RIGHTS, v. 20.10.2016, Nr. 7334/13 - Mursic v. Croácia).

73 GRIMM, Dieter. Europa ja - aber welches? In: RÜTTGERS, Jürgen; DECKER, Frank (Org.). Europas Ende, Europas Anfang. Neue Perspektiven für die Europäische Union. Frankfurt: Campus Verlag, 2017. p. 42. 
podem ser identificados nas decisões do Tribunal Constitucional, que se opõem à reivindicação de um controle de identidade; ${ }^{74}$ também o Brexit pode ser visto, em última análise, como uma resposta a isso.

A Corte Europeia de Direitos Humanos afirmou igualmente a supremacia da CEDH sobre o direito constitucional nacional, especialmente no caso Gladkov und Anchugov vs. Rússia, ${ }^{75}$ em que foi decidido sobre o direito de voto dos prisioneiros na Rússia, que contrariava expressamente um dispositivo de uma parte inalterável da Constituição russa. ${ }^{76}$ Nada obstante, a decisão Görgülü, de fato, fez escola, e foi adotada por um amplo número de tribunais constitucionais e tribunais superiores dos Estados-Membros, de modo que o embate sobre a última palavra de nenhuma forma está definido. ${ }^{77}$ A Corte Europeia de Direitos Humanos responde ao apelo para o duelo com uma oferta de diálogo. ${ }^{78}$ Ela evita o discurso da "última palavra", já que ele cria um impasse insuperável. Também o Tribunal Constitucional alemão nunca jogou a carta Görgülü, mas sempre se esforçou por uma troca viva na conexão do Tribunal Constitucional. ${ }^{79} \mathrm{Se}$ os ataques não forem em princípio ideológicos, mas relacionados a decisões individuais, o diálogo pode, de fato, funcionar, ainda que por vezes haja algum erro no contexto da argumentação jurídica. Último exemplo é uma decisão da Corte Suprema britânica, ${ }^{80}$ na qual a maioria rejeitou 0 acórdão da Corte Europeia de Direitos Humanos sobre a presunção de inocência. ${ }^{81}$ Neste sentido, a argumentação de Estrasburgo refletiria "hopeless and probably irretrievable confusion", akin to "a boat which, once severed from its moorings,

“A integração de um modo apolítico da interpretação do Tratado é contada como uma história de sucesso. E de fato ela é uma história de sucesso. Sem a contribuição do Tribunal de Justiça da União europeia, a União Europeia continuaria sendo uma Organização Internacional dentre muitas, com mais competências e densidade organizatória do que outras, mas não como um novum singular, o que hoje ela é. Porém a história de sucesso encobre diferentes aspectos. Muitos não conseguem se identificar com os resultados, já que por detrás do desenvolvimento judicial levado a efeito, não havia qualquer vontade política dos afetados. Eles não haviam sido perguntados, e responderam com uma retirada de legitimação".

74 Decisões do Tribunal Constitucional Alemão: 140, 317.

75 EUROPEAN COURT OF HUMAN RIGHTS, v. 4. 7. 2013, Nr. 11 157/04 und 15 162/05 - Anchugov and Gladkov v. Federação Russa, número de margem 50 - 53; Cf., também FLEIG-GOLDSTEIN, Rachel M. The Russian Constitutional Court versus the European Court of Human Rights. Columbia Journal of Transnational Law, v. 56, n. 1, 2017. p. 172.

76 Cf., sobre o conflito e as consequências, Hartwig EuGRZ 2017, 1; MALKSOO, Lauri. Russia's Constitutional Court Defies the European Court of Human Rights. European Constitutional Law Review, Cambridge, v. 12, 2016.

77 Pormenorizadamente em KELLER, Helen; WALTHER, Reto. The bell of Görgülü can't be unrung - can it. The Global Community Yearbook of International Law and Jurisprudence, 2020.

78 Biaggini EuGRZ 2014, 29; LÓPEZ GUERRA em MÜLLER, Amrei. Judicial Dialogue and Human Rights. Cambridge: Cambridge University Press, 2017. p. 401; SPANO, Robert. The European Court of Human Rights and National Courts. Nordic Journal of Human Rights, v. 33, 2015.

79 Voßkuhle NVwZ 2010, 1 (“A Conexão Europeia do Tribunal Constitucional”).

80 Hilary Term [2019] UKSC 2, 30. 1. 2019.

81 EUROPEAN COURT OF HUMAN RIGHTS (GK) v. 12. 7. 2013, Nr. 25 424/09 - Allen v. Reino Unido. 
floats out to sea and is tossed hopelessly this way and that", 82 e que não é, de acordo com o eufemismo inglês, precisamente amigável.

Para o modelo da Convenção Europeia de Direitos Humanos, estas três distinções centrais - a saber a ausência de um Estado, a ausência de uma organização estatal regulamentando questões específicas e o conflito insolúvel pela "última palavra" - fazem com que ela seja algo diverso em comparação a um convívio amplo regulamentado pela Constituição de determinado Estado. É como se fosse uma abóbada gótica, na qual falta a pedra angular. E, contudo, quase gostaríamos de dizer que "oh, um milagre ocorreu”. Deste modo, a CEDH assume as seguintes funções de uma Constituição - a função de legitimação, a função de integração, a função de delimitação, função organizatória, a função de identidade - sem ser uma Constituição, e sem querer ser uma. A CEDH desempenha suas funções em consonância com as 47 constituições dos Estados-Membros, e não em substituição a elas. ${ }^{83}$

O que ela é, então? Ela não é um “Tratado sobre uma Constituição da Europa”, um modelo na linha de ambos referendos fracassados que ocorreram em 2005 na França e na Holanda, mas de acordo com um Rousseau, um tratado sobre um modelo de sociedade, ou, caso aceitássemos esta formação de palavras, uma convenção de modelo para a sociedade. Uma construção híbrida e exitosa, uma sombra de Constituição. ${ }^{84}$

\section{A Corte Europeia de Direitos Humanos como Tribunal Constitucional ou como "Tribunal do Tratado do Modelo de Sociedade"?}

Com isso, finalmente, se coloca a pergunta sobre o status da Corte Europeia de Direitos Humanos. Ela é um Tribunal Constitucional, ou um guardião do consenso sobre um modelo de sociedade? Sem dúvida, a Corte Europeia de Direitos Humanos se equipara a um Tribunal Constitucional, um Tribunal Constitucional sem Constituição. "Tribunal Constitucional" não é um registro de marca protegido, de modo que existem várias formas, com distintas atribuições de competências, que estão posicionadas em diferentes níveis da estrutura constitucional; o espectro da categoria de Tribunal Constitucional abrange de órgãos

\footnotetext{
82 LORD WILSON (Hilary Term [2019] UKSC 2, 30. 1. 2019), número de margem 85.

83 Cf., Keller/Kühne ZaöRV 2016, 245 - 307; Walter ZaöRV 1999, 962, 966 e ss.

84 Desta forma conceituado por Stone-Sweet e Keller em STONE-SWEET, Alec; KELLER, Helen (Org.). A Europe of Rights. Oxford: Oxford University Press, 2008. p. 3.
} 
quase consultivos até Tribunais com decisões de cassação. Com a competência decisória última em questões que envolvem direitos humanos com fundamento na Convenção, com uma jurisprudência abrangendo milhares de casos, e que geram consequências em 47 ordens jurídicas europeias, o Tribunal contribui para a contínua diferenciação do modelo de sociedade pré-formado pela $\mathrm{CEDH}$, fazendo-a adaptável a novos desenvolvimentos sociais. Com isso, ela assume a função de um Tribunal Constitucional para a Europa, e é até mesmo mais visível e com eficácia mais sustentável do que alguns Tribunais Constitucionais, que têm à disposição uma autêntica Constituição como critério de interpretação. ${ }^{85}$ Neste contexto, é muito pertinente a metáfora da "sombra de Tribunal Constitucional" criada por Helen Keller e Daniela Kühne. ${ }^{86}$

\section{Crise e futuro}

Se estamos falando de um tratado de modelo de sociedade, então precisamos igualmente falar da crise do modelo de sociedade. Pois mesmo que o desenvolvimento tenha sido por muito tempo linear, e tenha levado à aceitação e aplicação de standards comuns, os sinais se evidenciam, de que o progresso linear não é nenhuma regularidade, e de que o desenvolvimento pode ser interrompido ou levar a uma direção oposta. Neste sentido, vale a pena retornar mais uma vez ao ano decisivo de 1979, e ao caminho adotado naquela oportunidade, não em consenso, mas por maioria de votos. Pois neste ponto - agora em retrospectiva -, já são identificáveis as primeiras rupturas. ${ }^{87}$

A Convenção é um "living instrument"? Não, dizem os críticos, e indicam os princípios da formação da vontade democrática, que se antepõem a uma formação judicial, cuja extensão e direção não são previsíveis. Além disso, não deve ser descartado, em termos metodológicos, que os standards podem ser novamente formados, caso o consenso europeu mude; o "dever ser" não deve ser dependente do "ser".

Os conceitos vagos da Convenção admitem uma interpretação aberta? Fitzmaurice condensou assim as reflexões: "Within certain limits almost anything can colourably be represented as connected with or related to some other given

Cf., Keller/Kühne ZaöRV 2016, 245, 293.

Keller/Kühne ZaöRV 2016, 245, 306.

87 Ver as análises da crítica contemporânea à Corte Europeia de Direitos Humanos realizadas nos estudos dos Estados: BREUER, Marten. Principled resistance against ECtHR judgments - A new paradigm? Berlim: Springer, 2019; POPELIER, Patricia; LAMBRECHT, Sarah; LEMMENS, Koen (Org.). Criticism of the European Court of Human Rights. Cambridge: Intersentia, 2016. 
thing". Não, dizem os críticos, uma interpretação extensiva não é por si mesma justificada, se ela tornou a proteção aos direitos humanos mais efetiva, porque ela restringiu a soberania do Estado.

A “margin of appreciation" é um instrumento no qual deva ser levado em consideração o princípio da soberania? Também aqui a resposta dos críticos é negativa, já que o resultado seria muito indeterminado.

Todos esses são sinais do que recentemente se designou como "principled resistance". ${ }^{88}$ Mas esse "principled resistance" vai mais além, e põe em xeque, nos seus pontos fundamentais, o modelo de sociedade garantido pela Convenção. A quebra de tabu no nível político é transposta para o nível jurídico. O credo sobre a liberdade de opinião, assim como foi formulado no Handyside mediante a famosa fórmula da aceitação de opiniões, "that offend, shock or disturb the State or any sector of the population",89 o credo de uma compreensão da liberdade religiosa, que se constrói pela tolerância e pelo pluralismo, ${ }^{90}$ não vale mais como irrestringível. O Tribunal se coloca de modo crescente na defensiva, e acende o sinal vermelho, especialmente com sua jurisprudência concernente ao art. 18, que prevê a proibição da má utilização do poder político. ${ }^{91}$ Também o comitê ministerial tomou um outro caminho, e pela primeira vez deu início, contra o Azerbaijão, ao procedimento designado de “opção nuclear”, conforme o art. 46, §4ํㅡㄹ da CEDH, um procedimento no qual o Tribunal foi instado a verificar se a violação ao tratado permanecia. $^{92}$

O Tribunal como guardião de um modelo de sociedade, que é construída nos limites de um rejeitado Leviatã, precisa, mais do que nunca, falar em uma linguagem clara. ${ }^{93}$ Parece como que se os debates fundamentais estivessem se repetindo. Como bem referido no começo, esses debates, do final da década de 1940 e início da década de 1950, foram, ao mesmo tempo, jurídicos e políticos.

88 Ver BREUER, Marten. Principled resistance against ECtHR judgments - A new paradigm? Berlim: Springer, 2019.

89 EUROPEAN COURT OF HUMAN RIGHTS, v. 7.12.1976, Nr. 5493/72 - Handyside v. Grã-Bretanha, número de margem 49.

90 "As enshrined in Article 9, freedom of thought, conscience and religion is one of the foundations of a 'democratic society' within the meaning of the Convention. This freedom is, in its religious dimension, one of the most vital elements that go to make up the identity of believers and their conception of life, but it is also a precious asset for atheists, agnostics, sceptics and the unconcerned. The pluralism indissociable from a democratic society, which has been dearly won over the centuries, depends on it. That freedom entails, inter alia, freedom to hold or not to hold religious beliefs and to practise or not to practise a religion" (EUROPEAN COURT OF HUMAN RIGHTS, v. 25. 5. 1993, Nr. 14 307/88 - Kokkinakis v. Grécia, número de margem 31).

91 Cf., especialmente EUROPEAN COURT OF HUMAN RIGHTS, v. 28. 11. 2017, Nr. 72 508/13 - Merabishvili v. Georgia; EGMR v. 15. 11. 2018, Nr. 29 580/12 - Navalnyy v. Federação Russa.

92 Comitê ministerial, resolução interina, v. 25. 10. 2017, Az. CM/ResDH (2017) 379.

93 Cf., também sobre isso, VOßKUHLE em STOCK, G.; MARKSCHIES, C.; HAUER, S. (Org.). Zukunftsort: Europa. Berlim: De Gruyter, 2015. p. 135-148. 
Naquele tempo, era necessário um código de valores para a Europa (ocidental), pois havia um código de valores para a Europa (oriental) considerado como ameaçador. Hoje, as linhas divisórias não são mais tão claras. A pergunta "quanto de Europa" é, ao mesmo tempo, a pergunta "quanto de direitos humanos"? $\mathrm{E}$, para ela, de fato, a resposta só pode ser inequívoca.

\title{
The European Human Rights Convention - a Constitution for Europe?
}

\begin{abstract}
In retrospect, the initial scepticism about the European Convention on Human Rights and the new system created for the protection of human rights is surprising. Due to favorable historical circumstances, its development exceeded all expectations. The jurisprudence showed revolutionary elements, which can be seen as indicative of a constitutionalisation. Although the ECHR also deals with the protection of democracy and the rule of law in the context of human rights, it cannot be considered a Constitution for Europe.
\end{abstract}

Keywords: European Convention on Human Rights. International Law. European Constitution. Human Rights. Constitutionalisation.

Contents: 1 Hope and Disillusion: the formation process - $\mathbf{2}$ Patience and Innovative Ideas: the slow maturation process of the ECHR - $\mathbf{3}$ Elements for Constitutionalization - $\mathbf{4}$ Constitution or Something Different? - $\mathbf{5}$ The European Court of Human Rights as a Constitutional Court or as a "Court of the Treaty on the Model of Society"? - $\mathbf{6}$ Crisis and Future - References

\section{Referências}

ASCHE, Josephine. Die Margin of Appreciation. Berlim: Springer, 2018.

BATES, Ed. The evolution of the European Convention on Human Rights. From its inception to the creation of a permanent Court of Human Rights. Oxford: Oxford University Press, 2010.

BESSON, Samantha. The extraterritoriality of the European Convention on Human Rights. Leiden Journal of International Law, v. 25, 2012.

BHUTA, Nehal (Org.). The frontiers of human rights: extraterritoriality and its challenges. Oxford: Oxford University Press, 2016.

Biaggini EuGRZ 2014, 29.

Binder, JRP 2015, 1.

BRATZA, Niklas. European Human Rights Law Review, Oxford, v. 2, 2014.

BREUER, Marten. Principled resistance against ECtHR judgments - A new paradigm? Berlim: Springer, 2019.

CHURCHILL, Winston. Discurso para a juventude acadêmica de 19 de setembro de 1946. Disponível em: https://rm.coe.int/16806981f3.

DOTHAN, Shai. Judicial deference allows European Consensus to Emerge. Chicago Journal of International Law, v. 18, 2018. 
DRÖGE, Cordula. Positive Verpflichtungen der Staaten der Europäischen Menschenrechtskonvention. Berlim: Springer, 2003.

DZEHTSIAROU, Kanstantsin. European consensus and the legitimacy of the European Court of Human Rights. Cambridge: Cambridge University Press, 2015.

FLEIG-GOLDSTEIN, Rachel M. The Russian Constitutional Court versus the European Court of Human Rights. Columbia Journal of Transnational Law, v. 56, n. 1, 2017.

FROWEIN, Jochen. European integration through fundamental rights. Michigan Journal of Law Reform, Ann Arbor, v. 18, n. 1, p. 5-27, 1984. Disponível em: https://repository.law.umich.edu/mjlr/vol18/iss1/2/.

GERARDS, Janneke; BREMS, Eva (Org.). Procedural review in European fundamental rights cases. Cambridge: Cambridge University Press, 2017.

GLENDON, Mary Ann. A world made new: Eleonor Roosevelt and the Universal Declaration of Human Rights. New York: Random House Trade, 2001.

GREER, S. C. The Interpretation of the European Convention on Human Rights: Universal principle or margin of appreciation? UCL Human Rights Review, Oxford, v. 3, 2010.

Hartwig EuGRZ 2017, 1.

HENNE, Thomas; RIEDLINGER, Arne (Hrsg.). Das Lüth-Urteil aus (rechts-) historischer Sicht. die Konflikte umVeit Harlan und die Grundrechtsjudikatur des Bundesverfassungsgerichts, 2005.

Hilary Term [2019] UKSC 2, 30. 1. 2019.

JANKOWSKA-GILBERG, Magdalena. Extraterritorialität der Menschenrechte. Berlim: Nomos Verlagsgesellschaft, 2008.

KELLER, Helen; WALTHER, Reto. The bell of Görgülü can't be unrung - can it. The Global Community Yearbook of International Law and Jurisprudence, 2020.

Keller/Kühne ZaöRV 2016, 245 - 307.

Keller/Kühne ZaöRV 2016, 245, 293.

Klatt ZaöRV 2011, 691.

KLEINLEIN, Thomas. Consensus and Contestability: The ECtHR and the Combined Potential of European Consensus and Procedural Rationality Control. European Journal of International Law, v. 28, 2017.

Krieger ZaöRV 2014, 187.

LAUTERPACHT, Sir Hersch. An International Bill of the Rights of Man. New York: Columbia University Press, 1945.

LEGG, Andrew. The Margin of Appreciation in International Human Rights Law: Deference and Proportionality. Oxford: Oxford University Press, 2012.

LETSAS. In: ETINSON, Adam (Org.). Human rights: moral or political? Oxford: Oxford University Press, 2018.

MACMILLAN, Margaret. Peacemaker. six months that changed the world. London: John Murray, 2003.

MALKSOO, Lauri. Russia's Constitutional Court Defies the European Court of Human Rights. European Constitutional Law Review, Cambridge, v. 12, 2016. 
MILANOVIC, Marko. Extraterritorial Application of Human Rights Treaties. Oxford: Oxford University Press, 2011.

MILANOVIC, Marko. From Compromise to Principle. Human Rights Law Review, v. 8, 2008.

MILANOVIC, Marko; PAPIC, Tatjana. The applicability of the ECHR in contested territories. International and Comparative Law Quaterly, v. 67, 2018.

MOWBRAY, Alastair. The development of positive obligations under the European Convention on Human Rights by the European Court of Human Rights. New York: Hart Publishing, 2004.

MOYN, Samuel. The Last Utopia: Human Rights in History. Cambridge: Harvard University Press, 2012. MÜLLER, Amrei. Judicial Dialogue and Human Rights. Cambridge: Cambridge University Press, 2017. Nußberger RW 2012, 197.

NUßBERGER, Angelika. The Concept of 'Jurisdiction' in the Jurisprudence of the European Court of Human Rights. Current Legal Problems, v. 65, 2012.

POPELIER, Patricia; LAMBRECHT, Sarah; LEMMENS, Koen (Org.). Criticism of the European Court of Human Rights. Cambridge: Intersentia, 2016.

PUBLIC PAPERS OF THE PRESIDENTS OF THE UNITED STATES. Jimmy Carter. 1977, v. 1. Washington D.C.: GPO, 1977. Disponível em: https://quod.lib.umich.edu/p/ppotpus?key=title; page=browse;value=j.

RÜTTGERS, Jürgen; DECKER, Frank (Org.). Europas Ende, Europas Anfang. Neue Perspektiven für die Europäische Union. Frankfurt: Campus Verlag, 2017.

Schaefer EuR 2017, 80-106.

SLOTERDIJK, Peter. Zorn und Zeit. Berlim: Suhrkamp Verlag, 2016.

SPANO, Robert. The European Court of Human Rights and National Courts. Nordic Journal of Human Rights, v. 33, 2015.

SPANO, Robert. The Future of the European Court of Human Rights. Subsidiarity, Process-Based Review and the Rule of Law. Human Rights Law Review, v. 18, 2018.

STOCK, G.; MARKSCHIES, C.; HAUER, S. (Org.). Zukunftsort. Europa. Berlim: De Gruyter, 2015.

STONE-SWEET, Alec; KELLER, Helen (Org.). A Europe of Rights. Oxford: Oxford University Press, 2008.

STOYANOVA, Vladislava. The Disjunctive Structure of Positive Rights under the European Convention on Human Rights. Nordic Journal of International Law, v. 87, 2018.

TERHECHTE, Jörg Philipp. Konstitutionalisierung und Normativität der europäischen Grundrechte. Tübingen: Mohr Siebeck, 2011.

TITIUN, Patrick (Org.). La conscience de droits: Mélanges en I'honneur de Jean-Paul Costa. Paris: Dalloz, 2011.

Tomuschat EuGRZ 2003, 95-100.

Unger-Sternberg AVR 2013, 312.

Voßkuhle NVwZ 2010, 1.

Walter ZaöRV 1999, 962, 966 e ss. 
Walter ZaöRV 1999, 962-983.

XENOS, Dimitris. The positive obligations of the state under the European Convention of Human Rights. Oxfordshire: Routledge, 2013.

ZaöRV 2015, 753-770.

ZUBIK, Marek (Org.). Human Rights in Contemporary World. Essays in Honour of Professor Leszek Garlicki. Warschau: Wydawnictwo Sejmowe, 2017.

Informação bibliográfica deste texto, conforme a NBR 6023:2018 da Associação Brasileira de Normas Técnicas (ABNT):

NUSSBERGER, Angelika. A Convenção Europeia de Direitos Humanos - uma Constituição para a Europa?. Direitos Fundamentais \& Justiça, Belo Horizonte, ano 14, n. 42, p. 49-73, jan./jun. 2020.

Recebido em: 14.05.2020

Aprovado em: 25.05.2020

Cota Convite 